\title{
TV UFSC - Considerações sobre a gestão de uma televisão pública em Santa Catarina
}

Cárlida EMERIM ${ }^{1}$

Fernando Antonio CROCOMO ${ }^{2}$

\begin{abstract}
Resumo:
Um importante argumento que respalda a histórica dificuldade de funcionamento das emissoras públicas brasileiras está no modelo de gestão que limita os ganhos e os investimentos, impactando diretamente na contratação de pessoal, equipamentos e, consequentemente, no conteúdo final. Há também a definição sobre o que é, do ponto de vista constitucional, uma emissora de televisão pública no Brasil. Não obstante, as televisões públicas universitárias, ligadas a uma instituição ou a um pool de universidades, desenvolvem produções e tentam, de diferentes formas, driblar os problemas. $\mathrm{O}$ artigo apresenta algumas fases de implantação da UFSC TV, hoje TV UFSC, que investe num modelo de produção considerado operacional e eficaz ao implantar a automatização em alguns processos e rotinas técnicas. Utilizando-se do modelo de pesquisa baseado na História Oral, articulada com o modo de ação do Jornalismo, mostra o percurso gerencial que culmina com uma proposta de permanência autônoma da emissora de televisão universitária pública na sociedade.
\end{abstract}

Palavras-chave: Televisão universitária. Conteúdo integrado. Gestão pública de emissora de TV. TV UFSC. História Oral.

\section{TV UFSC - Considerations on management of a public television in Santa Catarina}

\begin{abstract}
:
A important argument that supports the historical difficulty of Brazilian public broadcasters is in the management model that limits earnings and investments directly impacting the hiring of personnel, equipment and, consequently, the final content. In addition to this, there is also the definition of what is a public television station in Brazil from the constitutional point of view. Notwithstanding this process, public university television, linked to an institution or a pool of universities, develops productions and attempts, in different ways, to overcome problems. This article presents, through the historical course, some phases of UFSC TV implantation, now TV UFSC, that is investing in a production model considered operational and effective, which seems to allow a continuity by implementing automation in some processes and technical routines. Using the Oral History research articulated with Journalism (interview and investigation), show the managerial path that culminates with a proposal of autonomous permanence of the public university television station in society.
\end{abstract}

Keywords: University television. Integrated content. Public management of the TV station. TV UFSC. Oral History.

\footnotetext{
${ }^{1}$ Jornalista, Mestre em Semiótica, Doutora em Processos Midiáticos, professora e pesquisadora na Graduação (JOR) e Pós-Graduação em Jornalismo (PPGJOR) na Universidade Federal de Santa Catarina (UFSC).E-mail: carlida.emerim@ufsc.br

${ }^{2}$ Jornalista, Mestre e Doutor em Engenharia e Gestão do Conhecimento, professor e pesquisador no Departamento de Jornalismo (JOR) da UFSC. E-mail: fernandocrocomo@gmail.com
} 


\section{TV UFSC - Consideraciones sobre la gestión de una televisión pública en Santa Catarina}

Resumen:

Un importante argumento que soporta la histórica dificultad de funcionamiento de las emisoras públicas brasileñas está en el modelo de gestión que limita las ganancias y las inversiones impactando directamente en la contratación de personal, equipos y, consecuente, en el contenido final. También existe la definición sobre lo que es una emisora pública brasileña. A pesar las televisiones públicas universitarias, vinculadas a una institución o a un grupo de universidades, desarrollan producciones e intentan, de diferentes formas, transponer dichos problemas. El artículo presenta algunas fases de implantación de la UFSC TV, actualmente TV UFSC, que está invirtiendo en un modelo de producción considerado operativo y eficaz, implementando automatización en algunos procesos y rutinas técnicas. Utilizando el modelo de investigación basado en la Historia Oral junto con el modo de acción del Periodismo, mostra el recorrido gerencial que pone en manifiesto una propuesta de permanencia autónoma de la emisora universitaria pública en la sociedad.

Palabras clave: Televisión universitaria. Contenido integrado. Gestión pública de emisoras de televisión. TV UFSC. Historia Oral.

\section{Introdução}

O ano é 1998. No canal 15, da NET, uma empresa que oferta serviços de televisão por assinatura a cabo no Brasil, aparecia um aviso na tela que indicava ser aquele o canal universitário. Mas, ao invés de conteúdo, o que se via em Santa Catarina era apenas uma tela azul com o letreiro canal universitário. Em outros estados como São Paulo e Rio Grande do Sul, o canal universitário já funcionava, ora com uma universidade como operadora, ora com um grupo de instituições reunidas. A oportunidade de ter um espaço, um canal de televisão, para visibilizar conteúdo produzido nas universidades catarinenses motivou um grupo de servidores da Universidade Federal de Santa Catarina (UFSC), tanto professores quanto servidores técnicos, a tomar para si o desafio de implantar um canal universitário em Santa Catarina. Era o embrião da TV UFSC, que, hoje, mais de 20 anos depois, já faz parte da história da televisão pública do estado catarinense. Uma história com a qual a trajetória da TV UFSC tem muito a contribuir, principalmente se se pensar em modelos de gestão e de funcionamento mais autônomos.

Para restabelecer o percurso histórico da televisão universitária pública da Universidade Federal de Santa Catarina, a TV UFSC, o artigo emprega como condutor narrativo as diferentes fases pelas quais a emissora passou sob o ponto de vista dos modelos de gestão. Porém, esta história só pode ser contada a partir da própria história da televisão pública e educativa no estado. Cabe ressaltar que o objetivo deste artigo, além de trazer também este relato histórico de implantação, é o de contribuir para mapear as transições tecnológicas e os modelos de gestão implantados neste período de existência da TV UFSC. 
Para tanto, a pesquisa empregou uma articulação entre os métodos da História Oral, "que utiliza a técnica da entrevista e outros procedimentos articulados entre si, no registro de narrativas da experiência humana" (FREITAS, 2002, p.18). Os outros procedimentos envolvem a revisão bibliográfica (livros e artigos científicos) e a pesquisa documental em materiais de primeira mão (documentos e arquivos, particulares e/ou de empresas), bem como os já processados (jornais, revistas, documentários em vídeo ${ }^{3}$ e outros). Para o Jornalismo, a entrevista está na base de qualquer processo de produção, desde a apuração da pauta até a apresentação final da reportagem. É a fala dos entrevistados que referenda e respalda a atividade das notícias jornalísticas, que enfatiza a existência do fato no mundo real e dita de credibilidade o discurso jornalístico. Assim sendo, como técnica de busca de informações, a entrevista jornalística se aproxima da técnica de entrevista empregada na história oral, que também utiliza a entrevista como técnica fundamental. A história oral é:

[...] um método de pesquisa (histórica, antropológica, sociológica, etc.) que privilegia a realização de entrevistas com pessoas que participam de, ou testemunharam acontecimentos, conjunturas, visões de mundo como forma de se aproximar do objeto de estudo [...] Trata-se de estudar acontecimentos históricos, instituições, grupos sociais, categorias profissionais, movimentos, etc., à luz de depoimentos de pessoas que deles participaram ou os testemunharam. (ALBERTI, 1990 apud SILVA, 1999, p.118).

O presente artigo organiza-se apresentando, sinteticamente, como se estabeleceu o percurso de implantação da televisão educativa em Santa Catarina. Na sequência, mostra como foi concebido o canal universitário público, a TV UFSC, evidenciando as especificidades de cada uma de suas fases e os modos de gerenciamento ao longo de sua implantação. Para finalizar, ensaia-se uma proposta de gestão que parte exatamente do percurso e da experiência de funcionamento da TV UFSC.

\section{Das antenas repetidoras à emissora: breve contexto da televisão educativa em}

\section{Santa Catarina}

A televisão chegou a Santa Catarina quase 14 anos depois que já funcionava no Brasil e tem uma história inicial com versões diferentes. A partir de autores como Amorim (1984), Pereira (1985, 1992), Crocomo (QUERO..., 2013), Emerim e Cavenaghi (2014), Emerim e Moraes (2016), recuperam-se alguns dados históricos sobre a televisão e a

\footnotetext{
${ }^{3}$ É preciso informar que há um acervo de depoimentos, alguns já utilizados em produtos exibidos na própria TV UFSC ou em seu canal no Youtube, outros ainda inéditos. O presente artigo é um recorte dentro de uma pesquisa maior de restabelecimento histórico sobre a TV UFSC, que está sendo desenvolvida pelos autores, cujos resultados esperados são, além de artigos científicos, a redação de um livro e a realização de um documentário.
} 
televisão educativa em Santa Catarina. Na década de 1950, foram realizados alguns testes para a transmissão de imagens de televisão, mas somente em 1964, no centro da cidade de Florianópolis, é instalada a TV Florianópolis, a primeira experiência de televisão ao vivo de Santa Catarina e com programação local. Mas, segundo Pereira $(1985,1992)$ não se sabe ao certo se por a) questões políticas, b) burocráticas (falta de documentos necessários) ou por c) um forte temporal que danificou a antena de transmissão na época, a TV Florianópolis não completou um ano e foi fechada pelo Governo por não ter a licença de funcionamento autorizada. Assim, oficialmente, a primeira emissora de televisão aberta do estado catarinense surge em 1969 em Blumenau, a TV Coligadas, com um modelo de gestão comercial que intercalava a exibição da produção local com a programação nacional da TV Tupi.

O que se entende por televisão pública só foi implantada no estado quase 20 anos depois da primeira emissora comercial, no final dos anos 1980, em plena transição entre a ditadura e os primeiros movimentos de abertura democrática no país. A partir desta investigação, pode-se afirmar que em 21 de janeiro de 1988, Santa Catarina começa a receber o sinal da TV Educativa Canal 2, que transmitia a programação nacional da Funtevê4 com foco na cultura nacional, exibindo uma forte programação infantil, além de documentários, shows, entre outros. Antes da estreia, foi produzido um especial sobre a cultura e o estado catarinense, intitulado Verde Catarina, exibido várias vezes na programação nacional da Funtevê; mesmo assim, os catarinenses ainda não podiam contar com conteúdo local, conforme os autores já citados.

Ainda, segundo a pesquisa empreendida, no estado catarinense, o sistema integrado de televisões educativas operava com estações de transmissão (as famosas antenas repetidoras) em Florianópolis, Blumenau, Lages, Tubarão, Joinville e Rio do Sul, alcançando 43 municípios. Mas a programação local (regional) só passa a ser exibida com a implantação da TV Caracol, inaugurada em dezembro de 1992, ficando na história como uma das poucas emissoras de televisão do estado que operava em sistema de canal aberto com conteúdo eminentemente local, segundo Emerim e Moraes (2016) e Emerim e Cavenaghi (2014). Sardá (2012) afirma que a TV Caracol abriu um espaço importante junto à audiência catarinense, visto que exibia conteúdos regionais, a maioria ao vivo e

4 O Governo cria pela Lei 5.198, de 1967, a Fundação Centro Brasileiro de TV Educativa (FCBTVE), cuja função era a de expandir a TV educativa no Brasil e coordenar de forma político-administrativa o Sistema Nacional de Televisão Educativa, (SINTED), criado nos anos 1980, por meio da produção e distribuição de conteúdos (aulas, filmes, programas de entrevista, etc.). Em 1982, a FCBTVE muda a sigla para Funtevê. Dados obtidos pelos autores para este artigo. 
muito próximos aos interesses desse público local. A TV Caracol surge da experiência de uma televisão organizacional, a TV Executiva, órgão interno da empresa Telecomunicações de Santa Catarina (TELESC), que exibia informações de interesse interno da empresa e seus funcionários. O presidente da TELESC na época obteve a outorga de um canal em sistema aberto para operar na região da Grande Florianópolis e aproveitou a estrutura da TV Executiva, instalada na sede da empresa no bairro Morro da Cruz, adquirindo apenas um transmissor. Segundo Emerim e Moraes (2016) essa emissora acabou perdendo a concessão em 1993, em razão de denúncias de uso comercial com venda de espaços publicitários, sendo que o canal retornou à Fundação Roquette Pinto, TVE do Rio de Janeiro, permanecendo até hoje.

A partir de 1992, depois de um encontro em Florianópolis que reuniu tevês e produtoras universitárias, as duas universidades públicas do estado catarinense (a Universidade Federal de Santa Catarina e a Universidade do Estado de Santa Catarina), iniciaram um movimento para pleitear a instalação de um canal educativo no estado, tentando junto à Fundação Roquete Pinto a cedência/concessão de um canal de sinal aberto. Em razão do impedimento para que instituições de ensino operassem nesse tipo de empresa, uma das alternativas foi a de constituir uma fundação de direito privado, a Fundação Catarinense de Difusão Educativa e Cultural Jerônimo Coelho, criada em final de 1994, quando surge a Anhatomirim TV Educativa, que mais tarde passou a chamar-se TV Cultura de Santa Catarina. Esta emissora funcionou oficialmente até dezembro de 2011, quando o canal foi devolvido para o governo. A atuação da emissora, marcada por altos e baixos, já estava precarizada, praticamente fora do ar, desde 20085. Ou seja, a Grande Florianópolis não tinha mais uma TV pública aberta.

A partir deste ponto, o artigo dedica-se a estabelecer o percurso cronológico de implantação e desenvolvimento da TV UFSC, que nasce UFSC TV.

\section{O canal universitário na lei do cabo brasileira - nasce a UFSC TV}

Com a implantação do sistema de cabeamento para a distribuição de sinais de dados, televisão, rádio e internet no Brasil, em 1995, o governo aprova a Lei 8.977/956, a Lei do Cabo, que, entre outras prerrogativas, obrigava as empresas operadoras a

5 A história da Anhatomirim TV Educativa de Santa Catarina pode ser melhor compreendida a partir do artigo de Emerim e Moraes (2016), referidos na bibliografia.

6 Por lei, o canal universitário só pode funcionar com universidades da cidade, assim, somente em

Florianópolis. Mas atualmente, com o processo digital, há transmissão em outras cidades periféricas e até do interior do estado. 
disponibilizar canais comunitários para a população local. Como já se ressaltou anteriormente, em 1998, em Santa Catarina, o canal 15 da NET, ou seja, só para assinantes, estava disponível como canal universitário, destinado às instituições de ensino superior, mas não era utilizado.

Esse movimento de utilizar o canal para divulgar materiais da universidade partiu de quatro funcionários da UFSC: os servidores técnicos João Alberto Vieira da Silva e Luiz Roberto Barbosa com as professoras Sidneya Gaspar de Oliveira, na época, ouvidora da Universidade, e Maria de Nazaré de Matos Sanches, Pró-Reitora de Extensão da UFSC. Na ocasião, Luiz Roberto, que era diretor da área de eventos da UFSC, soube da disponibilidade do canal pela NET e, no primeiro semestre de 1998, trouxe a proposta para o grupo, que escreveu o projeto e apresentou ao Reitor da UFSC na época, professor Rodolfo Pinto da Luz.

A proposta de criação do canal da UFSC também contou com o apoio da Agência de Comunicação Social (AGECOM), com a participação do então diretor Moacir Loth e do Departamento de Jornalismo, por meio do professor Fernando Crocomo. A TV, num primeiro momento, ficou ligada à Pró Reitoria de Extensão, como um projeto de extensão.

Assim, foi criado o canal universitário, batizado de UFSC TV, e, para viabilizar a programação, foi feito um mapeamento de todo o acervo de vídeo da universidade pelo grupo, com a listagem de originais e cópias, que seriam os produtos a serem exibidos na programação. Isso permitiu que a equipe pudesse estruturar a própria emissora e as novas produções. Os materiais iniciais consistiam em algumas produções do Curso de Jornalismo e outras do Larus7, projeto que havia sido ligado à AGECOM. O Larus tinha uma estrutura técnica com câmeras e equipamentos avançados para captura de imagens e som subaquático. Outro laboratório que também contribuiu com o acervo inicial foi o Laboratório de Pesquisa em Imagem e Som (LAPIS), vinculado ao Departamento de História.

O grupo pioneiro também enviou cartas sondando as universidades sediadas em Florianópolis naquela época sobre o interesse em integrar o canal universitário público. Como as respostas das entidades foram negativas, a UFSC passou a ser a única integrante do canal que, portanto, passou a se chamar UFSC TV. Sendo a UFSC a única integrante, não foi necessário criar uma estrutura de regimento de um canal universitário, como

7 O Projeto Larus deixou de ser vinculado a AGECOM em 1993 para se constituir como instituto e, hoje, é uma Organização Não Governamental (ONG), que se mantém com recursos próprios e produz documentários sobre preservação do meio ambiente, principalmente o marinho, com exibição em televisões tanto educativas quanto comerciais. 
ocorreu com o canal universitário de São Paulo que, por ser integrado por mais de uma universidade, criou regras de uso e participação. A UFSC TV passou a seguir o regimento da própria Universidade Federal de Santa Catarina8.

Numa segunda etapa do processo de implantação, o professor Fernando Crocomo e o técnico em telecomunicação e eletrônica Manuel Rodriguez Alvar organizaram a lista de equipamentos necessários para montar o máster, uma espécie de gerenciador de transmissão dos programas e rodar a programação da UFSC TV. E o primeiro máster foi instalado dentro da NET, na sede da empresa em Florianópolis, na Avenida Rio Branco, sendo que no dia 10 de dezembro de 1998, a UFSC TV começava a emitir sua programação pelo canal 15 da tevê a cabo por assinatura, em comemoração ao dia da universidade pública.

Para que a estrutura da emissora se localizasse mais próxima ao polo emissor da NET, foram negociadas três salas na sede da Delegacia do Ministério da Educação (MEC), em Santa Catarina, dirigida pelo professor da UFSC, Jacó Anderle, cujo prédio ficava na rua Dom Joaquim, número 757, centro da cidade de Florianópolis. As salas foram cedidas, mas pouco antes da mudança da UFSC TV para a sede da Dom Joaquim, foi anunciada a extinção da Delegacia do MEC no estado, o que fez o reitor entrar com um pedido de uso do prédio em regime de comodato para a universidade instalar a TV e desenvolver outras atividades acadêmicas. O pedido foi atendido e o prédio está com a UFSC até a presente data.

Mas, voltando à estrutura de funcionamento, o prédio era localizado próximo à sede da NET, que ficava na Avenida Rio Branco. Isso permitiu o envio do sinal por microondas para a NET, que então distribuía via cabo a programação da UFSC TV. Depois de se instalar no prédio, a estrutura foi montada com o equipamento de reprodução (o máster já citado) e câmeras e ilhas de edição que foram sendo compradas aos poucos, inclusive com projetos subsidiados de emendas ao orçamento da União, encaminhadas pelo então deputado federal por SC, Édison Andrino, do Partido Democrático Brasileiro (PMDB), bem como verbas de editais específicos junto ao governo e aos órgãos de fomento, federal e estadual.

8 Em 27 de junho de 2017, o Conselho Universitário da UFSC aprovou um regimento específico para a TV, bem como regulamentou o Conselho de Programação da emissora, disponíveis, respectivamente, em: https://repositorio.ufsc.br/bitstream/handle/123456789/133630/Regimento\%20TV\%20UFSC.pdf?sequen ce=1\&isAllowed=y e https://repositorio.ufsc.br/handle/123456789/133631. 
As equipes eram formadas por professores, servidores técnicos administrativos e alunos que se inseriam como bolsistas. Do ponto de vista da forma de gerenciamento, como já se apontou antes, a UFSC TV funcionava como um projeto de extensão e a captação de recursos era viabilizada por meio de projetos e de editais (de extensão e de outras modalidades) junto à UFSC ou instituições de fomento externo, tanto federal quanto estadual. Tais recursos permitiam a contratação de bolsistas, a compra de equipamentos específicos para a televisão e de materiais de consumo.

No organograma da época, a coordenação geral ficava responsável pela busca dos recursos para manter a televisão no ar e a produção de programas, além de gestar junto a órgãos de fomento externo verbas para a compra de equipamentos e apoio financeiro para as produções dos programas. O administrativo contava com uma Coordenação Geral, exercida pela Pró-Reitora de Extensão, professora Maria de Nazaré; uma Coordenação Executiva, com Sidneya Gaspar de Oliveira; e três Diretorias/Coordenadorias: a Técnica, com João Alberto Vieira da Silva; a Administrativa, com Miguel Arcângelo Broering; e a de Programação e Programas, com Fernando Crocomo (depois substituído pelo professor Áureo Moraes); além da secretária Liliane Regina Régis e do Coordenador do Máster, Carlos Emílio, conhecido como Miloca.

Funcionários trabalhavam sem gratificação extra, eram servidores que tinham interesse em eletroeletrônica, em artes, (como na produção de cenários, elementos cênicos, etc.), e em produção de pautas em geral. Outro aspecto é que muitos tinham interesse em participar de um projeto novo, uma televisão universitária que seria exibida via televisão por assinatura. Professores com expertise em som, que eram do laboratório de acústica da UFSC, montaram o projeto acústico do estúdio, com isolamento das salas, cabeamento e fiação. O primeiro funcionário especializado em produção de televisão foi Farouk Custódio Salomão, servidor público federal (diretor de televisão) da TVE do Rio de Janeiro que veio transferido para a UFSC TV.

Em termos de equipamentos, a UFSC TV começou a operar com câmeras analógicas, pois o sistema do máster era analógico, em formato Super VHS (SVHS), um sistema um pouco superior aos videocassetes caseiros da época, os VHS. A transmissão, como já se apontou, era realizada em micro-ondas, de modelo ponto a ponto - ou seja, somente para transmissão fixa de sinal - que saía da sede da UFSC TV para a sede da NET, ambas localizadas no centro da cidade, sem processo de atraso do sinal.

A programação nesse período inicial tinha na grade principal os programas da TV SESC/SENAC, uma emissora educativa, ligada ao Serviço Nacional de Aprendizagem 
Comercial (SENAC) e ao Serviço Social do Comércio (SESC), que não tinha representação na cidade. Os programas eram, na maioria, gravados, porém, quando havia investimento em programação ao vivo, ocorria sempre no estúdio da emissora, em razão de não dispor de link para transmissão ao vivo em ambiente externo. Como já se afirmou antes, a programação local exibia dois programas produzidos pelo Curso de Jornalismo: o Minuto no Campus, exibido no horário dos intervalos da programação, e o Universidade Aberta na TV (Unaberta), que iniciou semanal e, depois, passou a ser diário, assumindo um formato de telejornal.

Outros programas foram o Descobrindo Floripa, uma produção com alunos formandos, e o Justiça do Trabalho na TV, o primeiro programa de entrevista mais formal que depois foi abrindo o leque de convidados e despertando o interesse do público. As vinhetas de intervalo, visto que na televisão universitária não se tem a exibição de comerciais, eram um espaço criativo, e ocupado com produções locais como, por exemplo, o professor e poeta Alcides Buss declamando um poema à beira mar, assim como os vídeos documentários produzidos pelo projeto Larus, já explicitado anteriormente.

Entre 2004 e 2008, a UFSC TV passa a ser coordenada pela Secretaria de Ensino a Distância (SEAD). É nessa fase que ela passa a se chamar TV UFSC. Nessa época, a TV começa a exibir programas para Educação à Distância, principalmente com transmissões ao vivo do estúdio, além de filmes de domínio público e a exibição de alguns trabalhos de conclusão de curso de Jornalismo, de Cinema e de outros cursos que finalizam seus estudos com produções audiovisuais. A programação local ainda era restrita e a emissora enfrentava alguns problemas técnicos para mantê-la, tendo em vista que o exibidor tinha pouca capacidade de armazenamento e não garantia muitas horas de programação.

\section{TV UFSC: a fase da nova estrutura rumo a digitalização e automação}

Em 2008, o reitor Álvaro Toubes Prata havia assumido a Reitoria por um período de quatro anos. Como era oriundo da área tecnológica, Prata buscou alternativas para apoiar a TV UFSC, pois, no início de 2009, a TV UFSC estava no ar, mas a programação predominante era da SescTv9 de São Paulo, com poucos programas produzidos

9A nomenclatura desta emissora inicia com TV SENAC, depois passa para TV SESC/SENAC e, atualmente, mudou para SescTv, ligada à rede SESC de São Paulo, pelo menos até o final da escrita deste artigo (2019). 
localmente. A equipe estava reduzida a apenas uma funcionária, a secretária Liliane Regina Régis, agora Coordenadora Administrativa, com o apoio de apenas uma bolsista do curso de Cinema.

Uma das propostas foi a de envolver pesquisadores da área da televisão digital da UFSC para reestruturar a TV, reunindo o grupo de pesquisadores que havia participado das discussões e das pesquisas que ajudaram na definição do Sistema Brasileiro de TV Digital (SBTVD), em 2005. Este grupo da TV digital desenvolveu um projeto, liderado pelo professor Aldo von Wangenheim, criando o Instituto Nacional para Convergência Digital (INCoD).

O projeto do INCoD foi contemplado com recursos para pesquisas em TV Digital, garantindo a compra de equipamentos para TV com sistemas em alta definição, incluindo câmeras, equipamentos para edição, exibição, um transmissor digital, bem como recursos para pagamento de bolsas de iniciação científica e de outras modalidades para a pesquisa na área. Começavam as primeiras mudanças que viriam a caracterizar a TV UFSC.

Nessa mesma direção, a administração da universidade decidiu criar, pela primeira vez, uma direção para a emissora, ocupada, em março de 2009, pelo professor Fernando Crocomo, do Curso de Jornalismo que, embora jornalista, atuou como gestor, no cargo de diretor da emissora. O servidor técnico Dilney Carvalho da Silva (Peri Carvalho), operador de câmera, foi transferido para a TV UFSC e vários bolsistas de estágio monitorado, de pesquisa e de extensão passaram a atuar na emissora. Foi essa pequena equipe a responsável por iniciar o processo de reestruturação técnica e administrativa da emissora universitária.

Os objetivos desse modelo de gestão buscavam integrar o funcionamento da TV em sintonia com o ensino, representado pelos alunos que passaram a atuar com mais frequência na TV; a extensão, valorizada pela produção e exibição de conteúdo efetivando sua função social e educacional; e, por fim, a pesquisa, que trouxe um cenário de vanguarda para a emissora, incentivando a descoberta de soluções que viabilizaram uma TV com uma estrutura enxuta, mas com qualidade em meio ao domínio das TVs comerciais.

A administração central, comprometida com o desenvolvimento da emissora, garantiu não só a transferências de mais profissionais, bem como a abertura de concursos públicos para a contratação de pessoal especificamente para atuar na TV UFSC. Com essa decisão, novos especialistas foram se integrando à equipe de reestruturação. 
O primeiro servidor contratado como jornalista a fazer parte da emissora foi Fábio Bianchini, depois Laura Tuyama; e, em outras áreas, também concursados o designer Andrei Krepsky de Melo, o técnico em audiovisual Jonatan dos Santos, o operador de câmera Cledison Marques e o técnico em informática Renato Irineu José.

Da AGECOM veio o experiente jornalista Artêmio Reinaldo de Souza; do Departamento Artístico Cultural (DAC), o cineasta José Henrique Nunes Pires (Zeca Pires). Da Universidade Federal da Fronteira Sul (UFFS) veio o técnico em audiovisual Felipe Laval Daniel, que, até a presente data, é diretor da emissora, ocupando o cargo que foi de Fernando Crocomo até então. Com a equipe montada, sistematizou-se um organograma inicial para começar a implantar as mudanças necessárias, como se pode ver na Figura 1, abaixo:

Figura 1 - Organograma inicial.

\section{ORGANOGRAMA INICIAL}
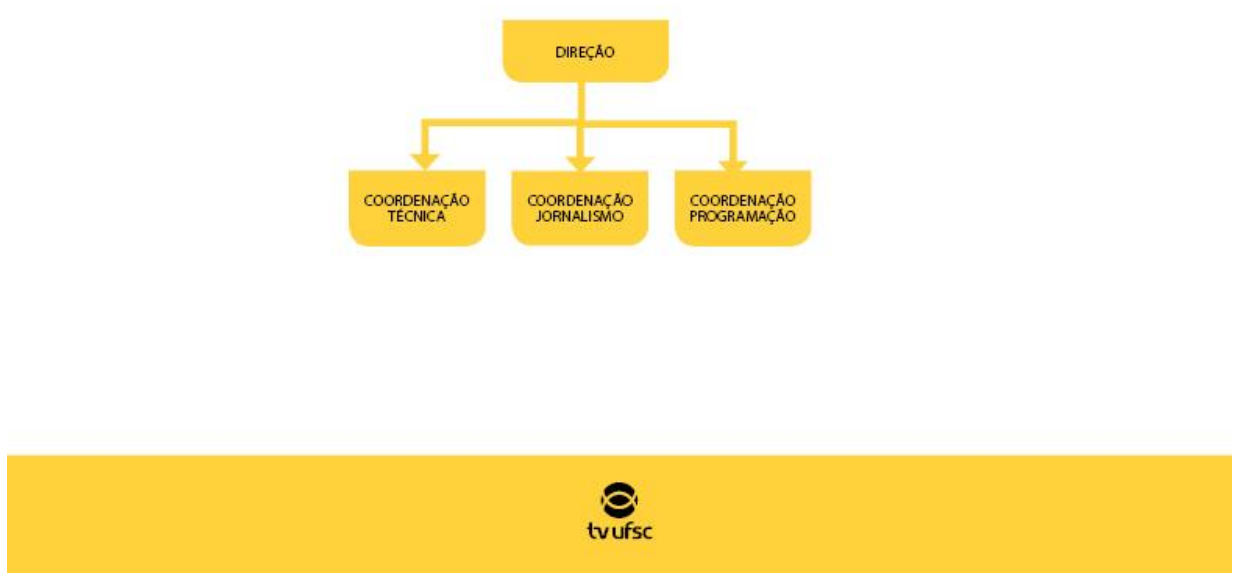

Fonte: Fernando Crocomo. 
$\mathrm{Na}$ Figura 2, vê-se a necessidade organizacional ideal para o funcionamento pleno da emissora.

Figura 2 - Organograma ideal.
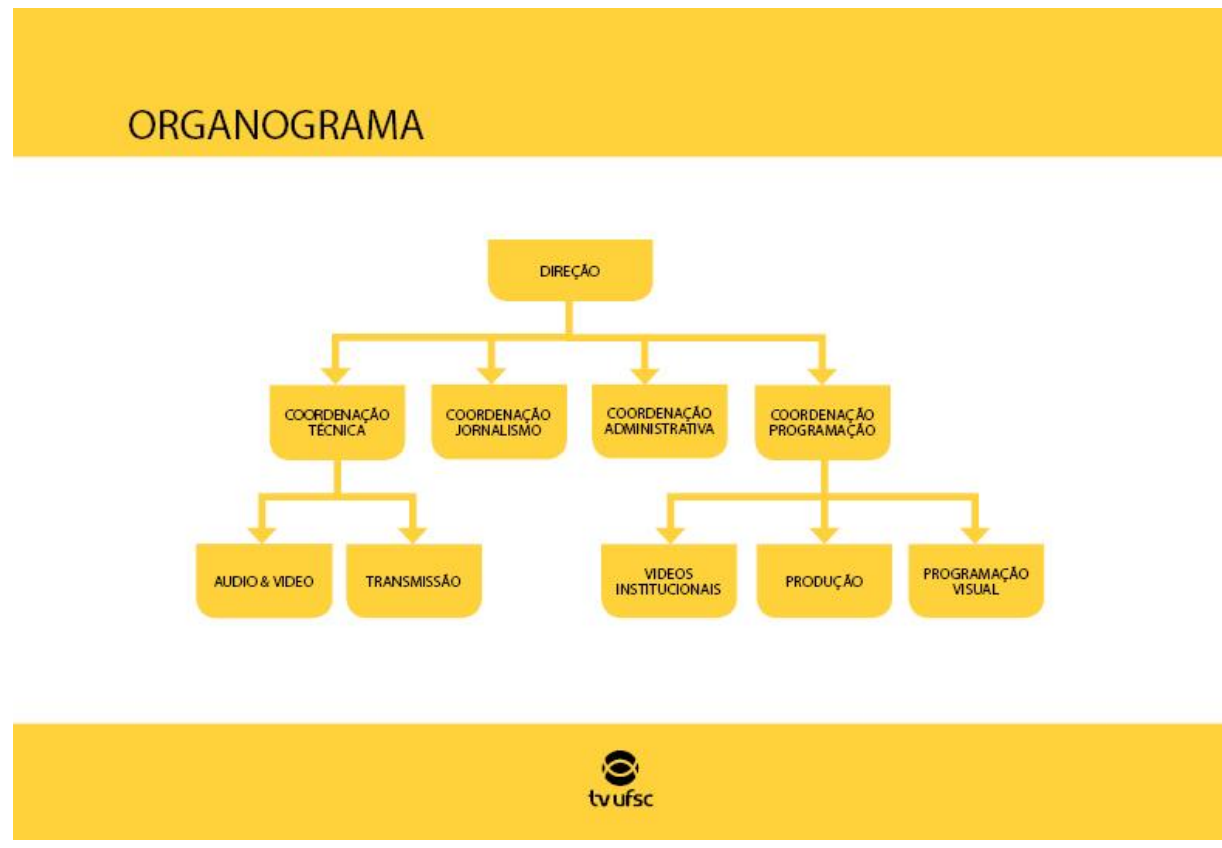

Fonte: Fernando Crocomo.

Aliado a este organograma, foi necessário definir e descrever as funções e as atividades que deveriam ser realizadas pela equipe que seriam importantes dentro de uma emissora de televisão com caráter educativo e público, como se demonstra na Figura 3: 
Figura 3 - Descrição de Funções e Atividades

\begin{tabular}{|c|c|}
\hline & ATVIDADES \\
\hline DIREC $\subset A O$ & - Planejamento e organizaçáo \\
\hline $\begin{array}{l}\text { COORDENACCAOAO } \\
\text { TECNICA }\end{array}$ & - Planejamento técnico; soluçđés técnicas; organizaçào e manutençào \\
\hline $\begin{array}{l}\text { COORDENACCAO } \\
\text { ADMINISTRATIVA }\end{array}$ & - Recursos humanos, organizaçáo do espaços; etc. \\
\hline $\begin{array}{l}\text { COORDENACAO } \\
\text { JORNALISMO }\end{array}$ & $\begin{array}{l}\text { - Produçáo jomalistica/divulgaçáo } \\
\text { - Responsabilidade editorial }\end{array}$ \\
\hline $\begin{array}{l}\text { COORDENACAAO } \\
\text { PROGRAMAÇAOO }\end{array}$ & - Definiçăo da programaçăo \\
\hline AUDIO \& VDEO & $\begin{array}{l}\text { - Soluçóes em áudio e video/exibidor de video/manutençáo } \\
\text { - Produçáo em estúdio/produçáo em externas }\end{array}$ \\
\hline TRANSMISSAO & $\begin{array}{l}\text { - Soluçóes em transmissáo } \\
\text { - Manutençąo }\end{array}$ \\
\hline VDEOSINSTITUCIONAIS & - Videos institucionais \\
\hline PRODUCAO & - Reportagensespeciais e documentários \\
\hline PROGRAMAÇAO VISUAL & - Identidade Visual \\
\hline
\end{tabular}

Fonte: Fernando Crocomo.

\section{Equipamentos e rotinas de trabalho}

Ainda em 2009, a TV UFSC adquiriu um novo exibidor com mais capacidade de armazenamento e, também, com a integração a uma mesa de controle denominada Matrix. Controlada pelo exibidor (um computador com boa velocidade de processamento para exibição de vídeos), a Matrix permitia alternar a exibição dos vídeos locais com o sinal da SescTv, recebido por satélite. Acontece que o sinal do satélite passou a sofrer interferência na antena de recepção. O sinal da SescTv estava ficando fora do ar por horas seguidas. A única alternativa da equipe foi a de colocar todos os programas possíveis no armazenamento do computador e rodar sem parar; ao terminar o último vídeo, o primeiro era retomado (loop). A surpresa veio dias depois, com o retorno de telespectadores que passaram a comentar a programação da emissora. Ficou claro que a repetição não era um problema, pelo contrário, passava a reafirmar a necessidade de programação local. $\mathrm{O}$ público mostrou que preferia ver reprises de assuntos locais a temas novos nacionais ou fora de seu contexto regional. Com essa configuração administrativa e técnica, de 2009 a 2013 a TV UFSC exibiu apenas programação local.

Em 2013, após acordo com a Empresa Brasil de Comunicação (EBC), a TV UFSC passou a alternar programas locais com a programação nacional da TV Brasil. A reitora Roselane Neckel deu continuidade ao projeto iniciado pelo reitor Prata e ampliou os esforços para a consolidação da emissora. O projeto do INCoD estava sendo 
implementado, com a instalação dos novos equipamentos e do transmissor digital. Com a experiência dos técnicos e com a disposição para pesquisa dos professores, várias alternativas foram encontradas para manter uma programação em alta definição na região da Grande Florianópolis. Era 18 de maio de 2013. A TV UFSC passou a transmitir não só o canal 15, fechado, na NET, mas também pelo canal digital 63.1, aberto e gratuito (a ultima TV pública em canal aberto na Grande Florianópolis tinha sido a TV Cultura, canal 2, analógico, como se disse no início).

Depois da experiência de 2009, que mostrou a necessidade de programação local, um sistema permitiu acessar o exibidor da emissora a partir de computadores remotos e inclusive de smartphones, possibilitando o controle do sistema de exibição de qualquer lugar, a qualquer tempo. Os espaços possíveis para a exibição de uma programação local foram ocupados. A grade de programação passou a ser feita com antecedência de mais de 10 dias. Dessa forma, mesmo sem operadores no final de semana, a programação local, alternada com a programação nacional da TV Brasil, passou a ser possível, sendo monitorada externamente.

A equipe passou a produzir novas edições dos programas UFSC Entrevista; cineastas do estado passaram a ceder seus filmes para o programa Cinema Catarinense; o resgate da história catarinense passou a ser visto no Canal Memória. O INCoD produziu o Conexão Saúde, série de vídeos com testes de diferentes modelos de interatividade com o público. Estudantes de design cederam seus trabalhos em vídeo para os intervalos. Muitos alunos de Jornalismo e Cinema preparam seus trabalhos de conclusão de curso em produção audiovisual pensando na exibição em alta definição no programa Primeiro Plano. Há também um investimento da emissora em produzir especiais, como os episódios para o programa Sonora, do Antropofonia; dos programas sobre arte na série $A$ Cor da Nossa Tela. Nos intervalos, uma série trata do problema da água, além do especial O Corredor das águas. O Jornalismo Científico é desenvolvido no programa Consciência e o jornalismo diário e factual, apresentado em dois modelos de programas: nos boletins do Universidade Já e no telejornal UFSC Cidade, entre outras produções. Toda essa grade de programação pode ser acessada no site www.tv.ufsc.br.

Com o apoio dos pesquisadores, a grade de programação é automaticamente transferida para o site e também para a tela interativa da TV, onde, com o controle remoto, é possível acessar as informações do vídeo exibido. Um software desenvolvido pelo mestre em computação Juliano Krieger, por meio do $\mathrm{INCoD}$, permite de maneira instantânea saber quantas TVs conectadas (ligadas à Internet) estão sintonizadas na TV 
UFSC. Todos os computadores da redação editam vídeos e estão interligados com o arquivo digital. É possível acessar o arquivo para edição, mesmo em outros prédios da UFSC. O material pronto é enviado via rede para o exibidor. Já o exibidor gera a transmissão que é enviada para o transmissor por três opções (por segurança): via streaming, fibra ótica e micro-ondas, como se pode ver na Figura 4.

Figura 4 - Estrutura da programação automatizada.

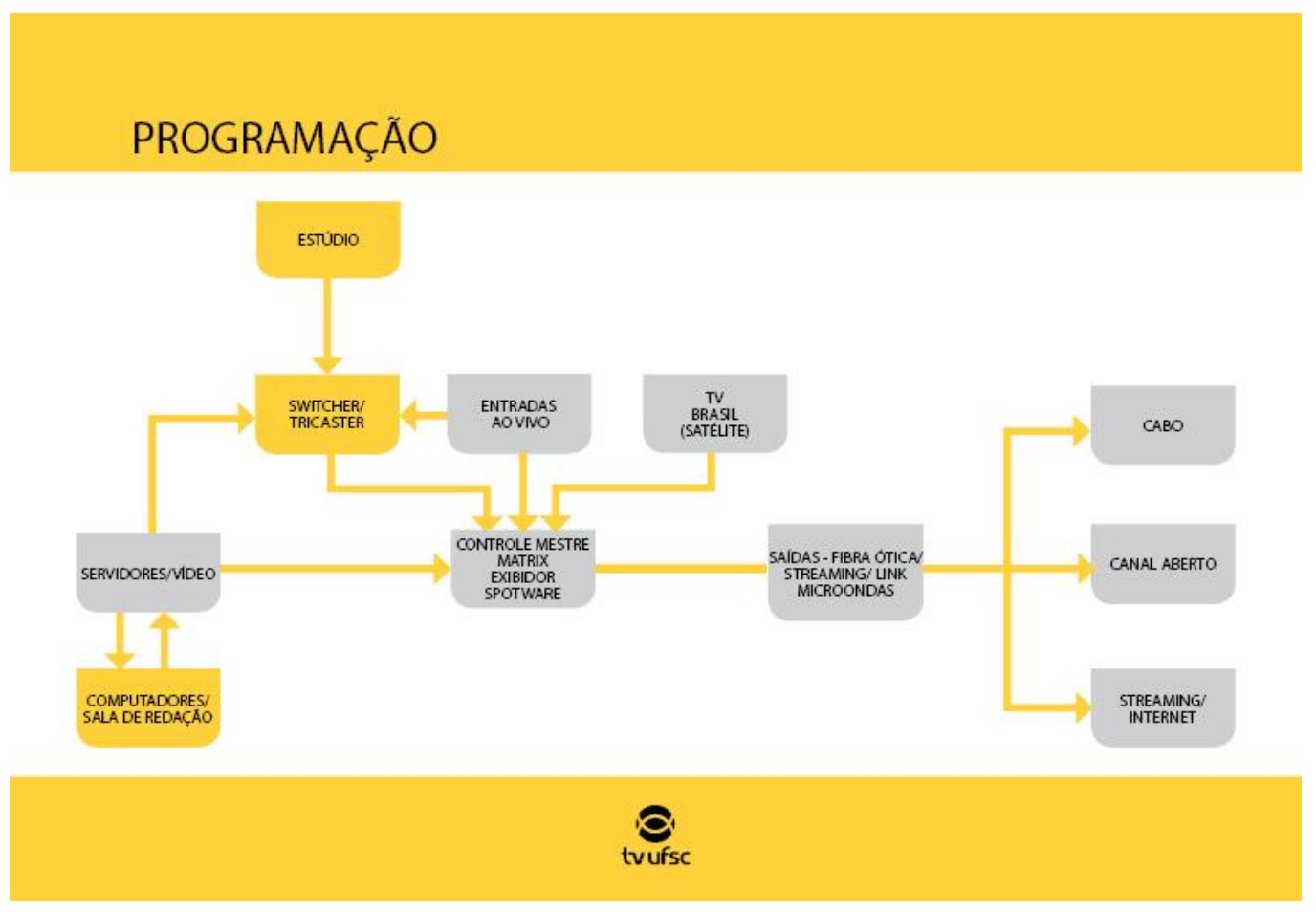

Fonte: Fernando Crocomo.

Dez anos se passaram desde o início da reestruturação da emissora. A equipe continua pequena e precisa ser ampliada, principalmente para garantir a manutenção da emissora no ar, bem como sua principal função social: a produção de conteúdo para a comunidade. Mas a resposta em busca de alternativas continua sendo a mesma que ajudou a transformação da TV UFSC: atender às necessidades da própria universidade. Não é possível tomar como parâmetro o modelo de uma TV comercial.

A necessidade dos alunos de graduação, tanto na área de produção de conteúdo (comunicação, artes, design, cinema, arte cênicas, etc.) como de informática e de engenharia (transmissão digital, por exemplo), pode contribuir para que a TV universitária púbica seja um espaço de aprendizado e que atraia investimentos que permitam seu crescimento. Porém, os resultados da exibição de produtos de qualidade e de interesse público também podem reverter em benefícios tanto para a própria emissora, 
para a universidade que a gerencia e para a sociedade que a assiste. Afinal, a pesquisa permite investigar inovações e desenvolver processos que não são estudados na rotina de tevês comerciais, que não têm tempo para este tipo de iniciativa, mas se interessam e precisam de soluções prontas. E, de quebra, essa infraestrutura e investimento também responde positivamente à imagem institucional da universidade e dos próprios financiadores/apoiadores.

A gestão integrada e a automação operacional são saídas que a experiência de eficácia da TV UFSC tem mostrado ser um modelo de sustentabilidade para a manutenção de uma proposta de televisão pública em canal aberto, de conteúdo regional, permitindo o fortalecimento em rede e o crescimento da comunicação e do jornalismo de qualidade para um público receptor cada vez mais ansioso por uma programação com a qual se identifique e reconheça.

\section{Referências}

AMORIM, Maristela. Os primeiros tempos da televisão em Florianópolis: a TV Florianópolis. 1984. Monografia. (Curso de Jornalismo) - Universidade Federal de Santa Catarina, Florianópolis, 1984.

QUERO luz: a TV Educativa na Grande Florianópolis. Direção de Fernando Antonio Crocomo. Florianópolis: Acervo da TV UFSC, 2013. Documentário (43 min).

EMERIM, Cárlida; CAVENAGHI, Beatriz Araújo. Os primórdios da televisão em Santa Catarina: mercado e produtos. Revista Brasileira de História da Mídia (RBHM). v. 3, n. 1, p.135-142, jan./jun./2014. Disponível em:

https://revistas.ufpi.br/index.php/rbhm/article/view/3982. Acesso em: 23 maio 2017.

EMERIM, Cárlida; MORAES, Áureo Mafra de. Memória da difusão pública: a Anhatomirim TV Educativa - a TV Cultura de SC. In: SANTOS, Nádia Maria Weber; MORAES, Ana Luiza Coiro (org.). TVs públicas: memórias de arquivos audiovisuais. São Leopoldo: Oikos, 2016. p. 268-280.

FREITAS, Sônia Maria de. História oral: possibilidades e procedimentos. São Paulo: Humanitas, 2002.

PEREIRA, Moacir. O golpe do silêncio. São Paulo: Global, 1985.

PEREIRA, Moacir. Imprensa e poder: a comunicação em Santa Catarina. Florianópolis: Lunardelli, 1992.

SARDÁ, Laudelino José. Entrevista em vídeo concedida em abril de 2012. In: CROCOMO, Fernando Antonio (dir.). Quero Luz: a TV Educativa na grande Florianópolis, 2013. Documentário. 43 minutos. Acervo da TV UFSC.

SILVA, Marcelo Kunrath. Uma introdução à história oral. (115-141). In: Cadernos de Sociologia, Porto Alegre, v. 9, p. 115-141, 1999. 
Submetido em: 22/08/2018

Aprovado em: 10/06/2019 